\title{
Ecologies of Space in the Paradoxes of Technology and Community
}

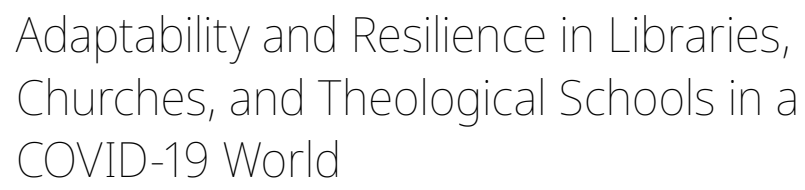

Anthony J. Elia, Southern Methodist University

\begin{abstract}
Technology has afforded both opportunities and threats that contrast the paradoxes of our world and impact our communities in ways that are often unintended. By considering the meanings and understandings of technology in the circumstances of church, seminary, and library, especially under stressful conditions, and provide a framework for individual and community adaptability and resilience, we allow for a hopeful, curative, and constructive way forward in our present world-to a place of meaningful belonging and participative community. The roles that theological libraries and churches play in adapting will reinforce the needs of the present and the strategies for the future of theological education itself-especially as we identify specific ecologies of space-those places that afford us the opportunity to restore and develop who we are as human beings and faith communities. Finally, we will look at all of this through the most unexpected lens of change and challenge confronting our world in the last six monthsthe lens of a world ravaged by the COVID-19 pandemic and how this has altered our conversation.
\end{abstract}

\section{A POST-COVID PREFACE}

The idea for this paper came well before the onslaught of the COVID19 pandemic. The entire idea of technology and community as it relates to churches and theological education and librarianship was of interest for some time and the concerns for discussion and consideration were relevant for some time. With the rise of a new working 
environment in a COVID and post-COVID world, we are pressed with a new framework within which to consider and think critically. The demand for work and study and communications to be done almost strictly through online platforms, especially videoconferencing like Zoom, and to some extent so-called hybrid environments, has made it imperative for us to consider these issues immediately and, in fact, with a greater sense of urgency. What many of us may have only felt fleetingly in the past has been put forcefully in front of us by the present world of Zoom meetings: it has forced us to recognize both the positives and negatives of telecommuting - the isolation, quarantine, and the virtual world of representation online, something that both humanizes and de-humanizes all at once the interpersonal spatial experience of education and theological experience.

\section{INTRODUCTION: A MEMORY OF LIFE WITHOUT TECHNOLOGY}

A few years ago, I drove through southern Indiana, deep into the Hoosier National Forest, and made my way to a secluded hilltop hamlet, not that far from the meandering Ohio River. The isolated spot was its own cloistered oasis in the rugged and wooded countryside called Saint Meinrad Archabbey. By the time I'd arrived at the guesthouse, checked in, and had a modest lunch, I found that my cellphone reception was failing and that my room had no modern technological amenities-no television, no radio, no phone. I was in a simple room, quiet, with two single beds, a reading chair, lamp, and a desk. There were ornaments of the cross on the wall. I had a couple books with me and a simple window looked out onto a modestly sloping hill spotted with tall white pines. As I settled in, I was ever more keenly aware of the quietude of the space and place as a whole. I ventured into the halls, which were also quiet, and went outside to walk around the grounds, which were lush green with gardens and full of majestic trees of all sorts. I went to the chapel and the abbey church itself. It was quiet everywhere, save for an occasional echo of a few people chatting in the distance-over on a bench, there on an outdoor patio, inside on some steps. I recall this time because of the distinct separation from technology in my life at that moment-the amenities, which we take so much for granted and which seem to be almost at the core of our modern existence. It was in this moment no more than a handful of years ago that I began to think about the real relationships between technology and the fundamental aspects of 
our life-how we perceive and understand the world; how we interact and communicate with other people; how we engage or disengage with our surroundings; how we are imprinted by the technological and digital social media that not only influence our quotidian thinking, but compel us into distinct and often Pavlovian behaviors to which we seldom admit. Additionally, the role that technology plays is not singular: it may enhance many things, like connectivity, speed, and communications, but it also has a side that, intentionally or not, moves us as members of multiple and diverse communities into mental, physical, intellectual, spiritual, and emotional spaces for which many of us are unprepared.

\section{WHY IS THE HUMAN SO IMPORTANT?}

The problems and paradox of technology and community are rooted in the nature of what it means to be human. We as people demand experience and interaction with other human beings in order to exist. The role of technology is that which mediates-it mediates the self, the human with the world around and outside us. It separates and extends the world away from us, while at the same time drawing it closer, through replication or alteration of physical space (e.g., how does a video call on Skype or Zoom bring a person in a Beijing cafe into my living room in Dallas?). And the paradox is that it both creates a barrier to reality and invents the illusion of reducing physical space. Our ability to speak over telephones or internet connections, hearing the voices or seeing faces of our friends and loved ones is just that: an illusion of space. And even though it creates this connective presence, that presence is only so real-not wholly, physically real, but an experience of presence without presence. Because we are tactile, visceral, and physical beings, the embodiment of our essences without actual embodiment is the crux of this paradox. Even when we attempt to use such things as artificial intelligence (AI) or virtual reality (VR), they may enhance these experiences, fooling our brains into considering something truly present and real, but they are not. They are doppelgängers and effigies, figments of a sort. When a colleague recently spoke of all the new (VR) equipment available to create virtual classrooms where it felt like you were "in the room" with other students, I first thought that would be a fascinating exercise; but I also thought "why are we trying to replicate the real with the unreal?" 
The questions of the Church, then, are those that ask about theological anthropology: what is the person? What is the human? The questions of the ancient church were ones of presence, constitution, and nature of the human being. What was Jesus Christ, God, or the Holy Spirit after all? It depends on which church or theologian you speak to-from which denomination or tradition. What, then, might this carry over into the modern and post-modern world? What, for instance, might presence mean, especially in such things as communion, if it is done online, virtually? Is it bona fide or permissible? Is it real? Indeed, as COVID-19 spread around the globe, Christianity Today was already diving into the touchy subject in an article titled "Online Communion Can Still be Sacramental: The Bread and the Cup Zoomed for You” (Chris Ridgeway, March 27, 2020). The article notes some interesting statistics, including a PEW research study that was cross-denominational. Among American Protestant ministers, 83\% "agree that viewing a livestream is an acceptable option for the sick." But why stop there? Everyone else seems to be going to "online" worship in this new age of COVID-driven liturgy. Of course, the problems arise around communion and the ideas of presence in the host. What is interesting in this piece is that the author discusses the issues and concerns of presence specifically, noting that "a daily digital culture has shaped our interactions to the point that human presence is not synonymous to physicality."

Many people already recognized this before the COVID pandemic struck and had a plethora of opinions about what this meant. In fact, many writers on the subject found technology a complicated agent of change that could both help and hinder our own social development-which we could extend to theological, ethical, and emotional development (see, for example, Combi 2016, who looks at "past and present" issues of digital technology and later the "problematic features" of digital natives, as well as Putnam 2000, Diamond 2019, Brownstein 2015, Antonucci 2017, and Boyle 2016). With the onset of the pandemic and the rapid need for a radical reworking of our educational, liturgical, and work environments, we have been forced to reconsider not simply the role of technology in our lives, but the question of its adaptability and how true or not our predictions were about digital and online environments. One of the primary outcomes of being forced into Zoom rooms for hours of disembodied meetings and classes is what is being called "Zoom Fatigue"-Julia Sklar at the National Geographic Magazine Online wrote an article titled "Zoom 
Fatigue is Taxing the Brain: Here's Why That Happens," in April 2020, which goes into the science of human cognition and adaptability to technological interfaces.

How, though, does this relate to the church, theological education, and theological libraries? And what are the intersecting points that are part of the larger questions at hand? Regardless of basic denominational factors, churches, seminaries (or theological schools), and theological libraries are each interconnected to one another for the purpose of serving communities of faith. Prior to the COVID pandemic, many colleagues in the ministry and theology fields would have discussions about how technology would best serve the church and congregations. Every theological school that I have ever worked at or been a part of has had extensive conversations about the role that technology should play in teaching, learning, and the formation of clergy, and theological libraries have sought in many cases to be ahead of the curve on technological advances over the yearswhether document delivery, demand-driven acquisition, or even virtual reality tools, among others. Part of the question, though, is that many of these institutions-churches, seminaries, and libraries-may be ahead of the game, while others are dreadfully far behind. Sometimes the church may have advances that outpace the seminary, or vice versa; or sometimes the library has advances that are more in line with the seminary, while the churches lag behind. In some cases, the issues in theological education are a result of a monoculture of tradition and content-driven focus that often shirks the advantages, advances, and dynamics of technological structures. In two decades of engaging with this topic, the theme has almost always been the same: technology is a "structure" that is a tertiary component subjugated by "content"-technology in itself is not seen as content. Yet, I would argue that if we were to look at technology as theology and theology as technology, each category would become both content and structure, and be more highly valued.

What this all means, then, is that in this triangulation of church/ school/library, the approaches and outcomes pre-COVID were in a holding pattern of complacency. Wherever we found the weakest points of this triadic structure, we would find the need to enhance technologies, communications, and outcomes-almost to a point where we were forever talking about "technology" and "change" without being bold innovators and implementors of that change. But since March 2020 and the rise of the global pandemic, our challenge 
has become slightly different-the fact that nearly every church, theological school, and library has had to close temporarily or have reduced hours or go to flex schedules, and in some cases had to lay off staff. This has required everyone to take technology seriously. This does not just mean "pay attention" to something a bit more-it means that it is integral to the way we operate, the way we perform, and the way we live. We also have begun to realize that technology is neither as easy or as demonstrably curative of our human ills as we may have thought. There are things, including the "Zoom fatigue," that we were unaware of for the most part. We have come to recognize the physical, physiological, psychological, and even emotional and spiritual pitfalls of being forced into these new spaces of digital human interaction.

Like many things in life, though, there are positives and negatives to all of this, and we make our way forward while negotiating these spaces and concerns. Pre-COVID, almost no one would have considered having "online church" with elderly relatives, who had suppressed vision or hearing loss-it was impractical, if not inconceivable. Yet, now not only is this becoming commonplace, there is anecdotal evidence that some church attendance has gone up-for there is no excuse for "not leaving your house" now. Though, of course, there are those who don't have internet at home, which is another issue altogether. For some, there is safety in home-based digital worship. For many introverts, the idea of distanced participation is attractive - a way to be amid the blessed community but remaining in the comfort zone of one's controlled home environment. A few months ago, I was set to give a few lectures in Dallas to a retirement group at a religious institution-I would have never imagined thinking it could work on Zoom, and yet that is what we had to do, and it had more participants and more questions than usual, many of them "Zooming” in from both the east and west coasts.

There are indeed many surprises to what has happened in 2020many are, in fact, positive. But there are the unforeseeable aspects of online theological encounters, the manipulation of digital space, and the psychological warping of our senses that come from our extended engagement with other people in virtual spaces. One aspect of our work in theological schools and libraries, which many people working in offices, higher education, finance, law, and other similar fields today may likely be experiencing, is this very issue of space-or, how this continuation of human presence in virtual form is holisti- 
cally affecting the human mind and body. Believe it or not, there is a long theological tradition that has dealt with this topic.

\section{WHAT IS SPACE AFTER ALL?}

In 1977, the philosopher Yi-Fu Tuan published a groundbreaking work on the themes of spatial embodiment titled Space and Place: The Perspective of Experience. In it, he covers areas including the role of space and place in the mind of children, the concept of crowds and crowding, our spatial abilities and how that relates to human knowledge, awareness of architecture and its impression upon our cognition, time and intimacy in spaces, our attachment to homelands, and how the visibility of spaces creates distinctions of place. What should not be surprising, then, is that the author begins this work with an introduction on Paul Tillich's theological roots and how they were informed by his childhood attachments to open visions of the Baltic Sea. We may not readily say that the Baltic Sea formed one of the most highly regarded works of 20th-century Protestant constructive thought-Tillich's Systematic Theology—but we cannot ignore that we are all informed by both space and place in the way that we think, read, write, and act in our lives. We are forged in experience, as Yi-Fu Tuan's work expresses, and, as most experiences are in the world (in contrast to dreams, for example), we are formed by that existence. Yet, since the emergence of the internet, the ideas of virtual spaces in relation to experiences and realities have long been considered, questioned, and debated. What, for example, does it mean "to experience" something virtually, digitally, or in an online environment? What is the difference between physical space and cyber-space? This is rhetorical, to some degree, so readers can answer in any number of ways. But this is to say that the elements of experience have taken on new turns and meanings in the last quarter-century or so. And now, because of a pandemic, we are forced to confront many of the questions like these that we hadn't thought really necessary to wrestle with-especially in religious and theological communities.

What do we mean by space and place in our lives and world? What value do they hold for us and what meanings do they convey? And how might they play into the roles of theology, theological education, and theological libraries? This is a salient point, because the question of space and place have deep theological importance to how we understand human connectivity to what we constitute as having 
meaning. Human beings associate with space and place, giving these physical locales meaning-sometimes elevating the "three-dimensionality" of our world to the sacred, creating sacred spaces. Houses of worship, chapels, tombs, sacred ground, memorials, monuments, and the earth itself constitute the array of the human attachments to the divine. So, our projections about space and place are not merely descriptions but transcendent environments that are informed by our very real human interactions in those dimensions. When we take real space and place away, when we "virtualize" spaces, something is lost.

The question of the sacred has been debated since time immemorial, and in the last few centuries by scholars of religion. In some cases, we can describe sacred space as a location that mediates between the profane, the living, and the sanctified, divine. But one might also argue that "sacred space" is the place on earth where we encounter one another and find in that encounter the physical presence of our breathing, pulsing, living humanity-in some ways like the approach Martin Buber took in his works, most notably Ich und $\mathrm{Du}$ (I and Thou; 1923), where divinity and sacredness was in other people and the encounters we had with them. Our essences of being human are tied up in the physical—being is what it means to be us, to be human. When the craft of the ancient Greek techne, made famous by Heidegger, extends our humanity to a place that is both us and not us at the same time (as in a video-chat), we are creating distinctions that echo the curious oddity of how the ancient Greeks played around with the origins of our souls and bodies (as Plato suggested). These philosophies influenced the dynamic and often confusing jumble of early Church debates about essence, being, and doublenature. Our existence in Zoom (or "Zoomtopias" as I like to call them) is two-dimensional disembodied embodiment-which is to say, we are given the appearance of ourselves and our nature, but without actually being of anything. What would the Greeks or Patristic writers have said about all this today?

\section{ECOLOGIES OF SPACE: REAL AND VIRTUAL}

What, then, are the ways forward for churches, theological schools, and libraries in the current environment? What are the trends, practices, and tips for consideration while we live through the uncertainty of COVID-19? And how might we best negotiate this new world that requires us to work in this paradox of technology and 
community - where we are brought closer together but, at the same time, distanced from the real embodiment of our colleagues, friends, and families? What does it mean to have church, but not the usual church functions and fellowship in person? What does it mean to have semesters of classes and seminars and chapel online, but not take communion in person or share in the community meals and events that remind us of our humanness? What does it mean to have services of reference, circulation, and research in a theological library, but done completely through technological means, where patrons cannot do their work in the physical library?

When first approaching this topic, the suggestions I had included the development of better and more sophisticated practices of communication and community-building that interwove the networks of church to seminary to library. This meant that we should do what some colleagues have called "technology evangelism.” But, since the pandemic, some things have changed. I still believe that these considerations of technological evangelism ought to be pushed-bluntly, we need to talk about and do better at incorporating technology into every aspect of these communities. The difference, though, is that, since the spring of this year, we have been forced to think very differently about technology, about presence, and about what it means to live and interact in not just hybrid work and research environments but in all of our environments.

The questions that we now must progress toward are questions of balance. As we have moved into the technological, we recognize that our spaces and places require us to navigate and determine how well we can function as human actors in these very spaces and places. We are adapting to new environments in ways that we either thought were not previously possible or not desirable. But because the pandemic has demanded our behaviors change, we have come to a point where we are looking at ecologies of space. Ecology is generally defined as "the relationships between organisms (e.g. people) with one another and their physical surroundings.” As we have seen in this discussion, the world heretofore has considered its surroundings as "physical" until recent times, with the advent of "virtual" spaces. But we can extend the definition of ecology to include new surroundings, just as we have experienced this new idea of the nonphysical world of the internet.

In these ecologies of space, we must continue to be active as individuals in the assessment and evaluation of what all spaces mean: 
the physical church and the virtual church, the physical seminary and the virtual seminary, the physical library and the virtual library. These ecologies demand that we better understand the relationships among communities and their environments-whatever those environments may be. If we consider how ecology proper has been studied and detailed, there are multiple levels of design: organismal ecology, population ecology, community ecology, and global ecology, for example. Applying the principles of such a design might help us, as individuals and communities, function better in our current circumstances. Furthermore, a consideration of what some scholars have considered a most important trait-resilience-may be what we must strive for most in this time of great stress and turmoil. As it relates to global ecologies and ecosystems, the work of Brian Walker and David Salt (2006), titled Resilience Thinking: Sustaining Ecosystems and People in a Changing World, is one of the most prescient and relevant pieces of scholarship that may guide us in our present time.

The principles for resilience are central to how we navigate through the COVID-19 pandemic and adapt accordingly, healthfully, and holistically. Being resilient is absolutely necessary in a time when our worlds of the physical and virtual are colliding and uncertainty is prevalent in office spaces, meetings, and planning strategies. These principles from Walker and Salt include the following: 1) maintain diversity and redundancy, 2) manage connectivity, 3) manage slow variables and feedbacks, 4) foster complex adaptive systems thinking, 5) encourage learning, 6) broaden participation, and 7) promote polycentric governance systems. How we may adapt to these principles for our communities will vary, but we can be creative and collaborative in finding the best approaches. The descriptions provided come from the aforementioned work and a review from the Stockholm Resilience Centre.

1) Maintain diversity and redundancy: "In a social-ecological system, components such as species, landscape types, knowledge systems, actors, cultural groups or institutions all provide different options for responding to change and dealing with uncertainty and surprise."

2) Manage connectivity: "Connectivity can be both a good and a bad thing. High levels of connectivity can facilitate recovery 
after a disturbance but highly connected systems can also spread disturbances faster."

3) Manage slow variables and feedbacks: "In a rapidly changing world, managing slow variables and feedbacks is often crucial to keep social-ecological systems 'configured' and functioning in ways that produce essential ecosystem services. If these systems shift into a different configuration or regime, it can be extremely difficult to reverse.”

4) Foster complex adaptive systems (CAS) thinking: "Although CAS thinking does not directly enhance the resilience of a system, acknowledging that social-ecological systems are based on a complex and unpredictable web of connections and interdependencies is the first step towards management actions that can foster resilience."

5) Encourage learning: "Learning and experimentation through adaptive and collaborative management is an important mechanism for building resilience in social-ecological systems. It ensures that different types and sources of knowledge are valued and considered when developing solutions and leads to greater willingness to experiment and take risks.”

6) Broaden participation: "Participation through active engagement of all relevant stakeholders is considered fundamental to building social-ecological resilience. It helps build the trust and relationships needed to improve legitimacy of knowledge and authority during decision making processes.”

7) Promote polycentric governance systems: "Polycentricity, a governance system in which multiple governing bodies interact to make and enforce rules within a specific policy arena or location, is considered to be one of the best ways to achieve collective action in the face of disturbance change."

Some of these principles may not be easily enacted. In fact, their presentation may require a fair amount of thought and preparation, but they are designed both to foster resilience and enhance the strength of community. The question for us today and in the coming years is, how might these principles provide us with a framework 
that helps us in this COVID and post-COVID world? How might we best negotiate the relationships between church, theological school, and library, especially where technology has roles in the way it forms or inhibits community? And how do we foster the best practice of life balance within a new world that hybridizes life, work, and school?

\section{WORKS CITED}

Antonucci, Toni, Kristine J Ajrouch, and Jasmine A. Manalel. 2017. "Social Relations and Technology: Continuity, Context, and Change." Innovation in Aging 1, no. 3 (November). dx.doi. org/10.1093\%2Fgeroni\%2Figx029.

Boyle, Mark. 2016. “Technology Destroys People and Places: I'm Rejecting It.” Guardian, December 19, 2016.

Brownstein, Ronald. 2015. "How Has Technology Changed the Concept of Community?” Atlantic, October 10, 2015. www. theatlantic.com/technology/archive/2015/10/community-in-thedigital-age/408961/.

Buber, Martin. 1923. Ich und du. Leipzig: Inselverlag.

Combi, Mariella. 2016. "Cultures and Technology: An Analysis of Some of the Changes in Progress-Digital, Global and Local Culture." In Cultural Heritage in a Changing World, edited by Karol Jan Borowiecki, Neil Forbes, and Antonella Fresa, 3-15. Springer. doi.org/10.1007/978-3-319-29544-2.

Diamond, Jared. 2019. Upheaval: How Nations Cope with Crisis and Change. New York: Hachette Books.

Putnam, Robert D. 2000. Bowling Alone: The Collapse and Revival of American Community. New York: Simon and Schuster.

Walker, Brian and David Salt. 2006. Resilience Thinking: Sustaining Ecosystems and People in a Changing World. Washington, DC: Island Press/The Center for Resource Economics. 